\title{
Effects of air temperature before harvest on the concentration of human adiponectin in transgenic strawberry fruits
}

\author{
Shoko Hikosaka ${ }^{1, *}$, Eiji Goto ${ }^{1}$, Noriko Tabayashi ${ }^{2}$, Takeshi Matsumura ${ }^{3}$ \\ ${ }^{1}$ Graduate School of Horticulture, Chiba University, 648 Matsudo, Matsudo, Chiba 271-8510, Japan; ${ }^{2}$ Agroscience Research \\ Laboratories, Hokusan Co., Ltd., 27-4 Kitanosato, Kitahiroshima, Hokkaido 061-1111, Japan; ${ }^{3}$ Bioproduction Research \\ Institute, National Institute of Advanced Industrial Science and Technology, Hokkaido, 2-17-2-1 Tsukisamu-Higashi, \\ Toyohira-ku, Sapporo, Hokkaido 062-8517, Japan \\ *E-mail: s-hikosaka@faculty.chiba-u.jp Tel \& Fax: +81-47-308-8842
}

Received August 15, 2018; accepted January 28, 2019 (Edited by K. Hiratsuka)

\begin{abstract}
Transgenic ever-bearing strawberry (Fragaria $\times$ ananassa Duch. 'HS 138') was cultivated in a closed plant production system to produce functional proteins that can enhance human immune functions. We investigated the effects of air temperature before harvest on fruit growth and the concentration of human adiponectin (hAdi) at harvest in transgenic strawberry. During the different stages of maturity (mature white and immature green stages), hAdi-expressing plants were exposed to four air temperature treatments $\left(15,20,25\right.$, and $\left.30^{\circ} \mathrm{C}\right)$ under 24 -h illumination provided by fluorescent lamps. Fruits were harvested at the mature red stage. The number of days to the mature red stage decreased with increasing air temperature, being the least at $30^{\circ} \mathrm{C}$. Fruit total soluble protein (TSP) concentration increased with decreasing air temperature, particularly at $15^{\circ} \mathrm{C}$, whereas fruit hAdi concentration tended to be higher under the $30^{\circ} \mathrm{C}$ treatment than under any other of the temperature treatments. There was no significant relationship between fruit fresh weight at harvest time and hAdi concentration within treatments, nor between the number of days to harvest and hAdi or TSP concentration. Although there were no significant differences in fruit hAdi content among treatments, hAdi production rate was the highest at $30^{\circ} \mathrm{C}$ because of the shortest duration to harvest. These results indicate that a higher air temperature promoted fruit maturation and accelerated the production of functional hAdi proteins in the fruit. For hAdi-expressing strawberry plants, exposure to $30^{\circ} \mathrm{C}$ may reduce energy consumption (lighting and air conditioning) for functional protein production under controlled environments.
\end{abstract}

Key words: closed plant production system, Fragaria $\times$ ananassa Duch., fruit weight, human adiponectin, pharmaceutical protein.

\section{Introduction}

Closed plant production systems have been used for the commercial production of seedlings and leafy vegetables in many countries, including Japan, Korea, and the USA. A few decades have now passed since the production of transgenic plants in a closed plant production system came to be considered as an acceptable technology for producing pharmaceutical and functional proteins that can be used to enhance the immune functions of humans and livestock (Goto 2011). Production of plant-made pharmaceuticals (PMPs) from transgenic plants has many advantages compared with the conventional production methods based on expression in other biological systems, e.g., animals, cells, or microorganisms (Daniell et al. 2001; Ma et al. 2003; Sack et al. 2015; Sainsbury and Lomonossoff 2014; Yao et al.
2015). Although the regeneration of stable transgenic plants is sometimes time-consuming, the notable advantage of this method is the stable expression (stable protein accumulation) compared with transient gene expression systems and edibility without intermediate extraction and filtration processes, when host plants are horticultural crops (e.g., lettuce, strawberry, and rice).

In this regard, there are many advantages to be gained in using strawberry plants (Fragaria $\times$ ananassa Duch.) as host plants to produce pharmaceutical and functional proteins. For example, strawberry plants can be propagated as a clone from a high-expressing transgenic mother plant, they require a relatively small cultivation space owing to compact plant size, and can grow under lower light intensities than field crops (Hikosaka et al. 2009). Members of our research group have previously introduced genes related to pharmaceutical and 
functional proteins into an ever-bearing strawberry (Fragaria $\times$ ananassa Duch. 'HS $138^{\prime}$ ), including those encoding bovine lactoferrin, bovine $\alpha$-lactalbumin, and human adiponectin (hAdi), which have been reported as pharmaceutical and functional proteins with respect to their anti-inflammatory activity (Yamaguchi et al. 2009) and/or prevention of lifestyle-related human diseases, such as diabetes and metabolic syndrome (Kadowaki et al. 2006; Newburg et al. 2010; Ushida et al. 2008). In our studies on transgenic and non-transgenic everbearing strawberry 'HS138' (host plant), the cultivation environmental conditions, such as light, air temperature, and $\mathrm{CO}_{2}$ concentration, were optimized from initial propagation (Hikosaka et al., 2009; Miyazawa et al. 2009) until the harvesting period (Hikosaka et al. 2013). Previously, we have reported the optimal environmental conditions for the production of the hAdi protein; however, the optimal conditions in terms of saving electrical energy and labor cost for PMP production, and thereby enhancing hAdi yield per energy consumption and labor cost, have not been studied.

In strawberry plants, fruit harvest generally continues simultaneously for several months or longer, and therefore growth rate and fruit size and quality invariably change through the cultivation period. As a strategy for minimizing the variation in growth rate and harvest fruit size, which may affect hAdi protein concentration in a fruit, we adopted a short cultivation cycle (within 4 months) by renewing plants three times per year. Additionally, as a host plant, we selected an everbearing strawberry, in which flowering can be promoted in a plant factory under the same conditions as those used for vegetative growth. However, many non-mature fruits remain on plants whenever the cultivation is terminated. If immature fruits (green and white fruit stages) contain the same amount of hAdi protein as mature red fruits, high air temperature treatment immediately prior to the end of the cultivation period may accelerate the coloring of immature fruits and thus increase the total yield of fruits and target protein. If we wish to control the growth rate of the leaves and fruits of transgenic plants, horticultural knowledge and cultivation techniques often provide useful information.

Generally, ambient air temperature during fruit development is known to be an important determinant of the growth and quality of many fruits and vegetables. For example, regardless of the strawberry plant type (non-transgenic June-bearing or ever-bearing strawberry plants), lower air temperature increases fruit weight and size at harvest time (mature red stage), whereas higher air temperature accelerates fruit coloring and shortens the harvest period (Ikeda et al. 2011; Kawanobu et al. 2011; Kumakura and Shishido 1994; Mori 1998; Toi et al. 2000; Wang and Camp 2000). On the basis of this horticultural knowledge of non-transgenic strawberries, we propose the following two hypotheses. Firstly, the possibility that exposure to low air temperature may also result in an increase in the size and weight of fruits of transgenic ever-bearing strawberry, and may increase the yield of the introduced target protein. Secondly, it is conceivable that exposure to high air temperature may result in smaller harvested fruit size, but a shorter cultivation period (i.e., number of days from anthesis to harvest) of transgenic strawberry, thus leading to an increase in the number of cultivation cycles and consequently a high yield of the target protein. However, at present it is not clear whether air temperature would affect fruit size at harvest and target protein accumulation in transgenic ever-bearing strawberry fruit.

Therefore, the purpose of this study was to examine the effects of air temperature before harvest on fruit weight and the content of a functional protein in transgenic ever-bearing strawberry in a closed plant production system. To elucidate the effect of air temperature on individual fruit size, color, and hAdi protein content with excluding the effect of an insufficient distribution of photoassimilates, we equalized the number of fruits per cluster and per plant among treatments.

\section{Materials and methods}

\section{Plant materials and treatment}

We used a transgenic line of ever-bearing strawberry (Fragaria $\times$ ananassa Duch. 'HS138,' Hokusan Co., Ltd.) into which the hAdi gene driven by the $35 \mathrm{~S}$ promoter had been introduced. The seedlings (plantlets) were propagated in vitro from a mother plant meristem and cultivated in a vessel until the third leaflet stage. After acclimatization to in vivo conditions for 3 days, seedlings were cultivated hydroponically until the flowering stage (the beginning of anthesis) under a 16-h photoperiod provided by white fluorescent lamps (FLs: FHF32-EX-N; Panasonic Co. Ltd.) in a closed plant production system. Photosynthetic photon flux density (PPFD) on the culture panel of the hydroponic container was set at $225 \mu \mathrm{mol} \cdot \mathrm{m}^{-2} \cdot \mathrm{s}^{-1}$. Air temperature was set at $25 / 20^{\circ} \mathrm{C}$ (light/ dark), relative humidity at $70 \%$, and $\mathrm{CO}_{2}$ concentration at $1000 \mu \mathrm{mol} \cdot \mathrm{mol}^{-1}$.

The nutrient solution (3.31 per plant) was prepared using a commercial fertilizer (M Hydroponic Research Co., Ltd.) at one tenth of the original concentration, and fresh nutrient solution was added twice per week to maintain an electrical conductivity (EC) of $0.5-0.7 \mathrm{dS} \mathrm{m}^{-1}$ and a $\mathrm{pH}$ of 5.5-6.5. The nutrient solution was renewed every 3 weeks.

In order to elucidate the effect of treatment duration under different air temperatures on individual hAdi strawberry fruit at different stages of maturity (mature white and immature green stages) without competition for photoassimilates, we limited the number of fruit clusters to one per plant and the number of fruits per cluster to two. In this experiment, plants bearing two 
fruits per cluster at different stages of maturation were exposed to four air temperature treatments $\left(15,20,25\right.$, and $\left.30^{\circ} \mathrm{C}\right)$ in four growth chambers. For each treatment, we used 10 to 16 transgenic strawberry plants containing the introduced hAdi gene. With the exception of temperature treatment and the 24-h light period, environmental conditions in the growth chambers were the same as those provided at the seedling stage.

We pollinated all flowers by hand and limited the number of fruits per cluster to two after confirmation of fruit-set with normal fruit shape. Experimental treatment was commenced when the primary fruit in a fruit cluster reached the mature white stage (the secondary fruit was then at the immature green stage, and measured approximately $5 \mathrm{~mm}$ in length) by moving plants from the cultivation area to chambers under the different air temperature treatments. Individual fruits at the mature red stage were harvested and treatment was terminated when the secondary fruit was harvested.

We harvested fruits and measured their fresh weight (FW). Thereafter, we cut the fruit into quarters, which were immediately frozen in liquid nitrogen and stored at $-80^{\circ} \mathrm{C}$ until measurement of hAdi and total soluble protein (TSP) concentrations. Additionally, for each fruit, we counted the number of days from the start of treatment to harvest.

\section{Protein extraction and detection of hAdi and TSP}

TSP was extracted from approximately $2 \mathrm{~g}$ of frozen fruit sample using $10 \mathrm{ml}$ of $50 \mathrm{mM}$ potassium phosphate buffer at pH 7.0 and $1 \%$ Triton-X100. The extracts were centrifuged at $20628 \times \mathrm{g}$ for $15 \mathrm{~min}$ at $4^{\circ} \mathrm{C}$. TSP concentrations in the extract supernatants were determined using a DC Protein Assay Kit (Bio-Rad Laboratories, Inc., USA), with diluted bovine serum albumin used as a standard. TSP was colorimetrically assayed in a microplate reader (MTP-450; Corona Electric Co., Ltd. JAPAN).

\section{Enzyme-linked immunosorbent assay analysis (ELISA)}

An ELISA assay kit (human Adiponectin/Acrp30 Quantikine ELISA Kit. R\&D Systems. USA) was used to determine the hAdi concentration in hAdi gene-introduced strawberry fruit. The fruits extracts were incubated in the ELISA plate, followed several washes and incubated with hAdi antibody according to a procedure manual of this kit. After the stopping reaction, the optical density was measured at $450 \mathrm{~nm}$ using a microplate reader (MTP-310lab,; Corona Electric Co.).

For each fruit sampled, we performed duplicate measurements of the concentrations of hAdi and TSP. Having determined the hAdi content in a fruit ( $\mu \mathrm{g} /$ fruit), the value was divided by the treatment period (days) for calculation of production efficiency ( $\mu \mathrm{g} \mathrm{d}^{-1} /$ fruit).

\section{Statistical analysis}

All data are presented as mean values. Treatment means were compared using the Tukey-Kramer test in Excel statistical analysis ver. 5.0 (ESUMI Co., Ltd.), and the level of significance was set at $p<0.05$.

\section{Results}

In all treatments, all primary fruits (starting from the mature white stage) were harvested earlier than the secondary fruits (starting from the immature green stage) (data not shown). Regardless of treatment duration for the fruits at different stages of maturity, the average number of days to harvest (mature red stage) from the initiation of treatment decreased with increasing air temperature, with the shortest period to harvest observed at $30^{\circ} \mathrm{C}$ (Figure $1 \mathrm{~A}$ ). For example, the maturation period of primary fruits at $15^{\circ} \mathrm{C}$ was $10-27$ days long, whereas that of secondary fruits was 20-38 days long. In contrast, at $30^{\circ} \mathrm{C}$, the fruit maturation period of primary fruits was only 5-11 days, whereas that of secondary fruits was only 8-15 days, which in both cases represented a significant reduction. The average FW of both primary and secondary fruits at harvest time was the highest at $15^{\circ} \mathrm{C}$, whereas there was no significant difference in $\mathrm{FW}$ among the other three treatments (Figure 1B).

On a FW basis, TSP concentrations increased with decreasing air temperature, particularly at $15^{\circ} \mathrm{C}$ (Figure $2 \mathrm{~A})$; however, the concentration of hAdi protein in
(A)

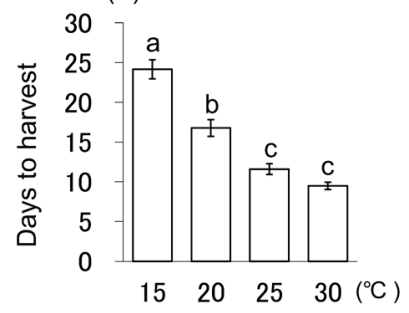

(B)

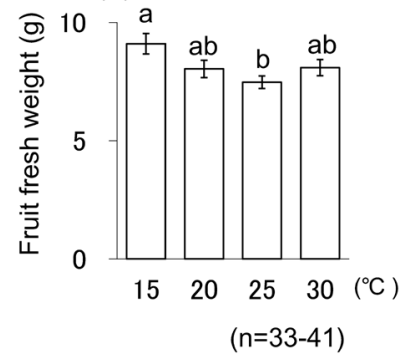

Figure 1. Effects of air temperature before harvest on days to harvest (A) and fruit fresh weight (B) in $h$ Adi-expressing ever-bearing strawberry fruits $(n=33-41)$. Vertical bars indicate SE. Different letters indicate significant differences among treatments at $p<0.05$ (TukeyKramer test).
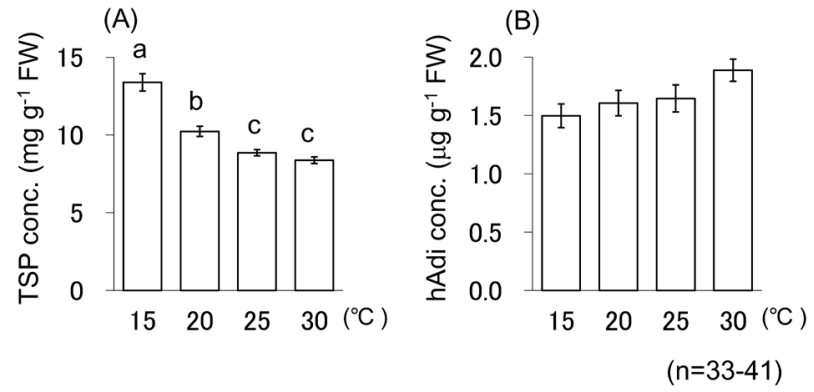

Figure 2. Effects of air temperature before harvest on total soluble protein (TSP) concentration (A) and hAdi concentration per fruit fresh weight (B) in $h A d i$-expressing ever-bearing strawberry fruits $(n=33-$ 41). Vertical bars indicate SE. Different letters indicate significant differences among treatments at $p<0.05$ (Tukey-Kramer test). 
fruit as a proportion of total protein content tended to be higher the $30^{\circ} \mathrm{C}$ treatment than under the other treatments (Figure 2B). Similar results were observed for the TSP and hAdi concentrations in fruit on a DW basis (data not shown). Consequently, the content of hAdi as a proportion of TSP increased with increasing

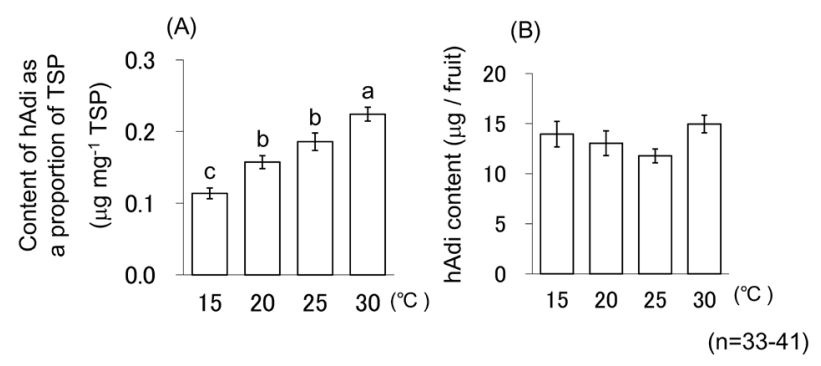

Figure 3. Effects of air temperature before harvest on the content of hAdi as a proportion of total soluble protein (TSP) (A) and hAdi content per whole fruit (B) in hAdi-expressing ever-bearing strawberry fruits $(n=33-41)$. Vertical bars indicate SE. Different letters indicate significant differences among treatments at $p<0.05$ (Tukey-Kramer test). air temperature, peaking at $30^{\circ} \mathrm{C}$, at which it was significantly higher than in any of the other treatments (Figure 3A). In contrast, there was no significant difference in hAdi content among treatments on a whole fruit basis (Figure $3 \mathrm{~B}$ ). The hAdi production rate was

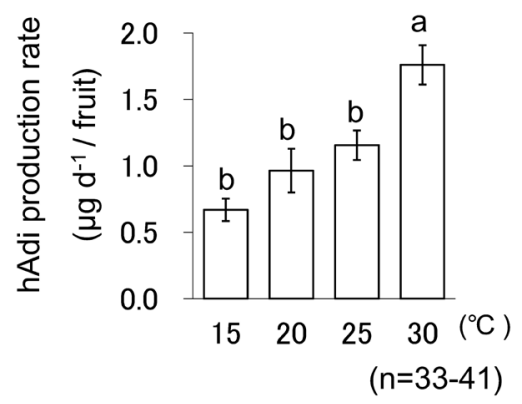

Figure 4. Effects of air temperature before harvest on hAdi production rate in $h$ Adi-expressing ever-bearing strawberry fruits $(n=33-41)$. Vertical bars indicate SE. Different letters indicate significant differences among treatments at $p<0.05$ (Tukey-Kramer test).
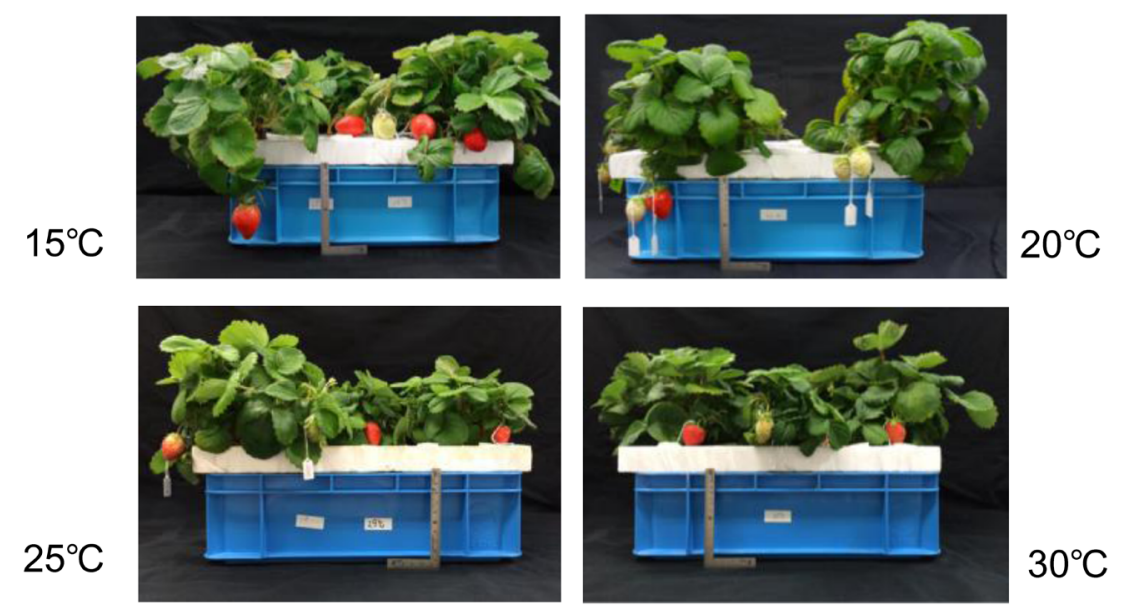

Figure 5. Harvest stage of primary fruits of hAdi-expressing everbearing strawberry fruits grown under four different air temperature treatments.
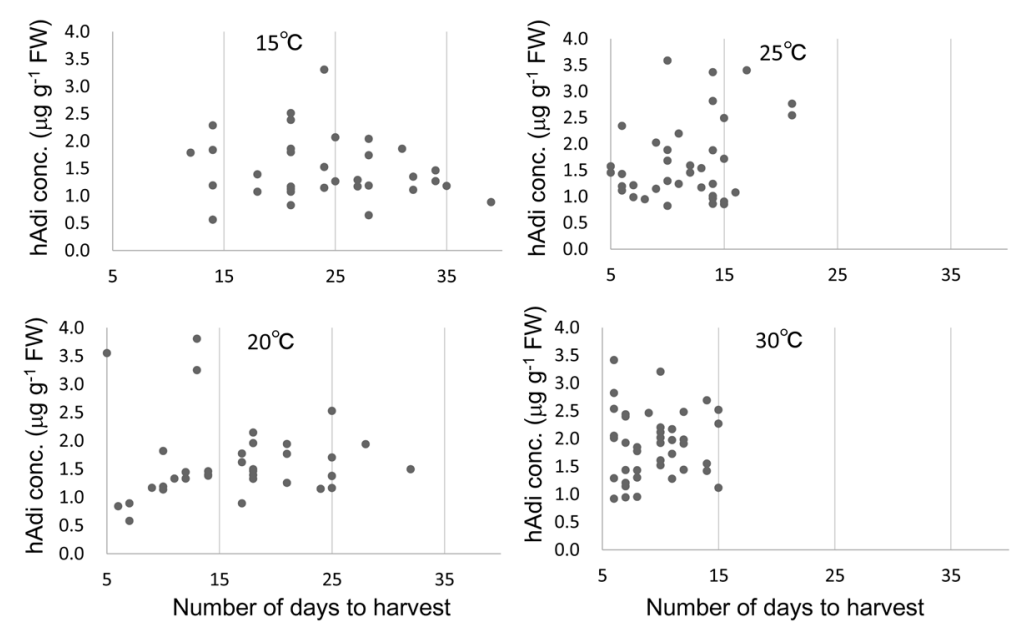

Figure 6. Relationship between the number of days to harvest from the start of treatment and hAdi concentration under four air temperature treatments in $h$ Adi-expressing ever-bearing strawberry fruits $(n=33-41)$. 
highest at $30^{\circ} \mathrm{C}$, concomitant with the shortest duration to harvest (Figure 4). In all of the treatments used in the present study, none of the plants showed any apparent temperature-related physiological disorders (Figure 5).

There was no significant relationship within treatments between either fruit FW at harvest time (mature red stage) and hAdi protein concentration (data not shown) or between the number of days to harvest and hAdi concentration (Figure 6) or TSP concentration (data not shown).

\section{Discussion}

The production of pharmaceutical and functional proteins by transgenic plants requires careful selection of the mother plant, not only with respect to target protein accumulation, but also from the perspective of the environmental responses of transgenic plants, which ideally should not differ substantially from those of nontransgenic plants when using well-established culturing techniques. Therefore, the hAdi-introduced 'HS138' strawberry cultivar used in the present study was selected based on high hAdi protein concentration as well as on its similarity to non-transgenic strawberry plants in growth rate and phenotype (flowering and maturation behavior).

In the present study, we observed that lower air temperature increased fruit fresh weight at harvest time (mature red stage), whereas higher air temperature accelerated fruit coloring (anthocyanin accumulation) and shortened the period to harvest. These observations are consistent with the findings of previous studies in which non-transgenic strawberry (including both June-bearing and ever-bearing types) were used as experimental materials (Ikeda et al. 2011; Kawanobu et al. 2011; Kumakura and Shishido 1994; Mori 1998; Toi et al. 2000; Wang and Camp 2000). On the basis of these results, we believe that the maturation and coloring responses of the hAdi-expressing strawberry fruits obtained in the present study under different air temperatures are similar to those of non-transgenic strawberries.

Many studies on the fruit quality of non-transgenic strawberry grown under low air temperature have reported high sugar (e.g., sucrose, glucose, and fructose) and anthocyanin concentrations, and low organic acid concentrations (Ikeda et al. 2011; Kawanobu et al. 2011; Wang and Camp 2000) compared with strawberries grown under intermediate and high air temperatures. Accordingly, exposure to low air temperature after anthesis is considered to be optimal for producing high quality non-transgenic strawberry fruits as fresh food.

In contrast, we anticipated that the transgenic everbearing strawberry examined in the present study would contain high hAdi protein content. Thus, if the hAdi strawberry can be cultivated at $30^{\circ} \mathrm{C}$, not only at the end of harvest but also throughout the harvest period (a few months), without suffering any physiological disorders, and the same hAdi protein yield can be produced within a shorter cultivation period than under conventional cultivation at $23^{\circ} \mathrm{C}$, this would enable important reductions in production costs due to decreases in electricity consumption and labor and to an increase in the potential number of crop cycles per year.

In many horticultural crops, including strawberry, high or low air temperatures can promote an increase in certain proteins, e.g., heat shock proteins, which constitute a well-known rapid-response group of peptides that function as molecular chaperones. Ledesma et al. (2004) reported that heat shock proteins appeared in the leaves and flowers of June-bearing strawberry in response to high air temperature. Koehler et al. (2012) identified 135 proteins in the crown tissues of nontransgenic strawberry, and in plants grown under low air temperature treatment, antioxidant/detoxifying enzymes increased in plants, including molecular chaperones, metabolic enzymes, pathogenesis-related proteins, and flavonoid pathway proteins, as cold tolerance-associated responses (Yong et al. 2008).

In our experiments, on a FW basis, TSP concentrations increased with decreasing air temperature, particularly at $15^{\circ} \mathrm{C}$. Cultivation at this temperature is assumed to activate protein production in the fruit to alleviate the low air temperature stress, thereby facilitating the successful completion of reproductive organ development, even though $15^{\circ} \mathrm{C}$ does not seem to constitute an extreme temperature when compared with treatments used in the aforementioned studies.

Although TSP concentrations increased in strawberry plants exposed to low air temperature, the concentration of hAdi protein in fruit tended to be higher under the $30^{\circ} \mathrm{C}$ treatment than in any of the other treatments, and hAdi content as a proportion of TSP content increased with increasing air temperature, peaking at $30^{\circ} \mathrm{C}$, indicating that the pattern of hAdi protein production differs from that of TSP. As an explanation for this differential response, we speculate that the higher hAdi concentration at $30^{\circ} \mathrm{C}$ could be attributed to enhanced transcriptional induction via the CaMV 35 S promoter in response to higher temperatures, as the activity of this promoter is known to be induced by various stimuli (Qin et al. 1994; Rowan et al. 2009).

Nevertheless, we observed no significant relationship within treatments between either fruit FW at harvest time and hAdi protein concentration or between the number of days to harvest and hAdi concentration or TSP concentration. These observations thus tend to indicate that hAdi protein accumulation was stable, and that on a FW basis, hAdi concentration was not 
influenced by fruit size or the number of days to harvest.

Interestingly, the highest hAdi production rate was observed at $30^{\circ} \mathrm{C}$, concomitant with the shortest duration to harvest. From the viewpoint of hAdi protein production efficiency in terms of the potential savings in electricity and labor costs, our results showed that higher air temperature (i.e., $30^{\circ} \mathrm{C}$ ) enhanced fruit maturation and accelerated the production of the functional hAdi protein in the fruit.

Additionally, shorter harvest cycles of hAdi strawberry fruits may lower the fruit load of the plant. In this regard, numerous studies have shown that heavy or long-duration fruit loads often cause reduced vegetative growth and altered dry matter distribution via a deficiency in photoassimilates, and consequently decreases in the size, quality, and total yield per plant of fruit (Correia et al. 2011; Heuvelink 1997; Hikosaka and Sugiyama 2005). The results of the present study suggest that high air temperature for less than a month does not only lead to an increase in the number of crop cycles per year but also to the maintenance of a balance between vegetative and reproductive growth by reducing the heavy fruit load, which is a feature of practical cultivation that produces many fruits per cluster.

Sakamoto et al. (2016) have shown that a high rootzone temperature $\left(30^{\circ} \mathrm{C}\right)$ inhibited strawberry plant growth and yield after 2 months under hydroponic culture due to decreases in root oxygen consumption and cell viability. In contrast, Gonzalez-Fuentes et al. (2016) reported that large fluctuations in root-zone temperature, rather than absolute differences in mean temperature, negatively affected strawberry plant growth and yield. Although we did not control root-zone temperatures in the present study, no temperature-related physiological disorders were observed under any of the treatments. However, if plants were to be grown at $30^{\circ} \mathrm{C}$, not only during the final harvesting stage but throughout the cultivation period, it would be necessary to monitor the effects of such treatment on plant and fruit growth and performance.

In conclusion, we found that a lower air temperature increased fruit weight at harvest time (mature red stage) and that a higher air temperature accelerated fruit coloring and shortened the harvest period in transgenic hAdi ever-bearing strawberry fruit. However, we detected no significant differences among treatments with respect to hAdi concentration as a proportion of fresh weigh. On the basis of these results, we established that exposing hAdi-introduced strawberry plants to $30^{\circ} \mathrm{C}$ may conveniently shorten the period of cultivation, thereby saving energy (lighting and air conditioning) and labor costs for the commercial production of the target functional protein.

\section{Acknowledgements}

This research was supported by a project from the Ministry of Economy, Technology and Industry of Japan (METI), "Development of fundamental technologies for production of highvalue materials using transgenic plants".

\section{References}

Correia PJ, Pestana M, Martinez F, Ribeiro E, Gama F, Saavedra T, Palencia P (2011) Relationships between strawberry fruit quality attributes and crop load. Sci Hort (Amsterdam) 130: 398-403

Daniell H, Streatfield SJ, Wycoff K (2001) Medical molecular farming: Production of antibodies, biopharmaceuticals and edible vaccines in plants. Trends Plant Sci 6: 219-226

Gonzalez-Fuentes JA, Shackel K, Heinrich Lieth J (2016) Diurnal root zone temperature variations affect strawberry water relations, growth, and fruit quality. Sci Hort (Amsterdam) 203: 169-177

Goto E (2011) Production of pharmaceutical materials using genetically modified plants grown under artificial lighting. Acta Hort 907: 45-52

Heuvelink E (1997) Effect of fruit load on dry matter partitioning in tomato. Sci Hort (Amsterdam) 69: 51-59

Hikosaka S, Sugiyama N (2005) Effect of fruit-load on growth patterns of fruit at the middle nodes of gynoecious-type cucumbers. J Hortic Sci Biotechnol 80: 130-134

Hikosaka S, Sasaki K, Goto E, Aoki T (2009) Effects of in vitro culture methods during the rooting stage and light quality during the seedling stage on the growth of hydroponic everbearing strawberry. Acta Hort 1011-1014

Hikosaka S, Yoshida H, Goto E, Tabayashi N, Matsumura T (2013) Effects of light quality on the concentration of human adiponectin in transgenic everbearing strawberry. Environ Control Biol 51: 31-33

Ikeda T, Suzuki N, Nakayama M, Kawakami Y (2011) The effects of high temperature and water stress on fruit growth and anthocyanin contents of pot-grown strawberry (Fragaria $\times$ ananassa Duch. cv. 'Sachinoka') plants. Environ Control Biol 49: 209-215

Kadowaki T, Yamauchi T, Kubota N, Hara K, Ueki K, Tobe K (2006) Adiponectin and adiponectin receptors in insulin resistance, diabetes, and the metabolic syndrome. J Clin Invest 116: 1784-1792

Kawanobu S, Wajima T, Zushi K (2011) Variations in sugar, organic acid and amino acid contents of strawberries (Fragaria $\times$ ananassa Duch.) under different growth seasons. Japanese Soc Agric Tech Manag 17: 131-135

Koehler G, Wilson RC, Goodpaster JV, Sønsteby A, Lai X, Witzmann FA, You JS, Rohloff J, Randall SK, Alsheikh M (2012) Proteomic study of low-temperature responses in strawberry cultivars (Fragaria $\times$ ananassa) that differ in cold tolerance. Plant Physiol 159: 1787-1805

Kumakura H, Shishido Y (1994) The effect of daytime, night time, and mean diurnal temperatures on the growth of 'Morioka-16' strawberry fruit and plants. J Jpn Soc Hort Sci 62: 827-832 (in Japanese with English Abstract)

Ledesma N, Kawabata S, Sugiyama N (2004) Effect of high temperature on protein expression in strawberry plants. Biol Plant 48: 73-79

Ma JK-C, Drake PMW, Christou P (2003) The production of recombinant pharmaceutical proteins in plants. Nat Rev Genet 
4: 794-805

Miyazawa Y, Hikosaka S, Goto E, Aoki T (2009) Effects of light conditions and air temperature on the growth of everbearing strawberry during the vegetative stage. Acta Hortic 817-820

Mori T (1998) Effect of temperature during flower bud formation on achene number and fresh weight of strawberries. J Jpn Soc Hort Sci 67: 396-399 (Japanese with English Abstract)

Newburg DS, Woo JG, Morrow AL (2010) Characteristics and potential functions of human milk adiponectin. J Pediatr 156(Suppl): S41-S46

Qin XF, Holuigue L, Horvath MD, Chua N (1994) Immediate early transcription activation by salicylic acid via the cauliflower mosaic virus as-1 element. Plant Cell 6: 863-874

Rowan DD, Cao M, Lin-Wang K, Cooney JM, Jensen DJ, Austin PT, Hunt MB, Norling C, Hellens RP, Schaffer RJ, et al. (2009) Environmental regulation of leaf colour in red 35S:PAP1 Arabidopsis thaliana. New Phytol 182: 102-115

Sack M, Rademacher T, Spiegel H, Boes A, Hellwig S, Drossard J, Stoger E, Fischer R (2015) From gene to harvest: Insights into upstream process development for the GMP production of a monoclonal antibody in transgenic tobacco plants. Plant Biotechnol J 13: 1094-1105

Sainsbury F, Lomonossoff GP (2014) Transient expressions of synthetic biology in plants. Curr Opin Plant Biol 19: 1-7
Sakamoto M, Uenishi M, Miyamoto K (2016) Effect of root-zone temperature on the growth and fruit quality of hydroponically grown strawberry plants. J Agric Sci 8: 122-131

Toi K, Nobuoka T, Hirayama Y (2000) Studies on fruit maturing in strawberry cultivar 'ASUKARUBY' (1) Relationships between fruit maturing period and temperature. Bull Nara Agr Exp Stat 31: 9-16

Ushida Y, Shimokawa Y, Toida T (2008) Effects of bovine $\alpha$-lactalbumin on ethanol-induced gastric mucosal inflammation in rats. Milchwissenschaft 63: 360-363

Wang SY, Camp MJ (2000) Temperatures after bloom affect plant growth and fruit quality of strawberry. Sci Hort (Amsterdam) 85: 183-199

Yamaguchi M, Yoshida K, Uchida M (2009) Novel functions of bovine milk-derived $\alpha$-lactalbumin: Anti-nociceptive and antiinflammatory activity caused by inhibiting cyclooxygenase- 2 and phospholipase $\mathrm{A}_{2}$. Biol Pharm Bull 32: 366-371

Yao J, Weng Y, Dickey A, Wang KY (2015) Plants as factories for human pharmaceuticals: Applications and challenges. Int $\mathrm{J} \mathrm{Mol}$ Sci 16: 28549-28565

Yong Z, Hao-Ru T, Ya L (2008) Variation in antioxidant enzyme activities of two strawberry cultivars with short-term low temperature stress. World J Agric Sci 4: 458-462 